\title{
Diverse socio-technical aspects of a digital archive of Aboriginal languages
}

\author{
Catherine Bow
}

Charles Darwin University, Australian National University

This is an Accepted Manuscript of an article published by Taylor \& Francis in Archives and Manuscripts on 17 February 2019, available

online: https://doi.org/10.1080/01576895.2019.1570282

\begin{abstract}
A socio-technical approach is taken to explore a digital archive of Australian Indigenous cultural heritage. The Living Archive of Aboriginal Languages is considered in terms of what it is currently doing and what it was intended to do. Two ethnographic stories focusing on user interactions and the outcomes of an online survey serve to evaluate the effectiveness of the Archive from the perspective of different users. This is then juxtaposed with a consideration of the original grant application, outlining what was envisaged for the project. This analysis serves to highlight some of the contingent relations and diverse socio-technical aspects of a specific knowledge infrastructure, as it allows multiple forms of interaction, new connections and generative activities as people discover, access and interact with the content now and into the future.
\end{abstract}

Keywords: Indigenous languages; digital archive; language maps; knowledge infrastructure; user interaction 


\section{Introduction}

Telling a purely historical story ... makes it possible to see the archive's complexity, but maybe difficult to see its contingency, its uncertain emergence from an ongoing, often fraught flux of ideas, technical possibilities and constraints, interests and agendas. ... (An alternative) perspective focusses upon the many different moment-by-moment decisions made by countless people who, little by little make it what it is: the occasional disagreement, the sudden insights of possibility, the technical hiccups, and the lucky breaks, and therefore how it continues to grow uncertainly, and how it may become frustrated in its attempts to fulfil the somewhat ill-defined purposes which, in our original funding application, we claimed it would serve. ${ }^{1}$

This remark comes from a 2014 paper describing the birth of the Living Archive of Aboriginal Languages, a digital archive of Australian Indigenous cultural heritage. The Living Archive of Aboriginal Languages project has collected and digitised thousands of texts in Indigenous languages of the Northern Territory (NT), and made them available online at www.livingarchive.cdu.edu.au. ${ }^{2}$ In this paper I foreground some of the diverse socio-technical aspects of the Archive, beginning with two stories of my experience sitting with users as they engage with the archive website, first an Aboriginal elder and language authority, and secondly a non-Indigenous teacher. These stories narrate users' responses which express both positive and negative experiences with the digital archive at that time. My commentary on these stories identifies several socio-technical factors that were influential in shaping the current form of the Living Archive, some of the 'contingencies' alluded to in the opening quote. Outcomes of an online survey are then used to highlight some of the socio-technical aspects raised in those stories. Following this, I reflect on the initial grant application document as a way of considering the emergence of the Archive at its beginnings, prior to my involvement as project manager. Juxtaposing what was imagined in initiating the project work that established the Archive with what has since been achieved enables an identification of diverse pushes and pulls that still influence the form the Archive takes today. The quotation above highlights the uncertainty involved in the production of a specific socio-technical knowledge infrastructure, in this case an online archive of Indigenous language teaching and learning materials. What was originally envisaged in the proposal to funders has emerged as something that somehow holds together, as users with radically different interests and purposes engage with it. The use of a sociotechnical approach highlights how the technical and 
the social are mutually constituted, formulating "a view of human culture that privileges neither the social nor the technological and in which neither is reducible to the other". ${ }^{3}$

The Living Archive project sits at the intersection of particular sets of archival practices of language documentation, Indigenous knowledges and the role of libraries and digital technologies, ${ }^{4}$ each of which bring their own sets of standards and assumptions. The Archive contains digital copies of many rare books in Indigenous languages. Many Indigenous communities in Australia currently engaged in language revival crave any extant records or documentation that may assist in expanding understanding of their language heritage. ${ }^{5}$ Digitising such materials is a practical means for reconnection with 'knowledge and information Indigenous people want to access for future utility, for creative endeavours and, importantly, for emotional and spiritual restoration of a people. ${ }^{6}$ While the materials in the Archive may hold a different significance for those whose languages are still strong, they are likely to contain multiple affordances for those who rely on older materials to connect with their language, now or in the future. Current uses of the Archive may not anticipate future uses - like the early missionaries or colonists who recorded wordlists of local Indigenous communities, with no idea of any future purpose they might be put to, archiving these resources allows them to become part of future knowledge-making activities.

Rather than viewing the Living Archive as a digital object which contains language materials, it is presented here as a knowledge infrastructure that enables various kinds of activity through the presentation of digital artefacts of Indigenous language and knowledge work. ${ }^{7}$ The infrastructure itself is a network of relations that keep things going, technically, politically, socially and ontologically, and can be analysed through a socio-technical lens which involves a meshing of the social, political and technical aspects of the Archive. Waterton identifies 'a move toward the exposure of the guts of our archives and databases, toward exposing the contingencies, the framing, the reflexivity, and the politics embedded within them. ${ }^{8}$ Star advocates analysing infrastructures using the tools of ethnographic fieldwork, and the present analysis can be considered a form of archival ethnography, ${ }^{9}$ which enables the complicated agency of the Archive to be problematised through tracing user narratives. The two user stories presented here are narrations of my own experiences on the field, the first told as a personal reflection some time after the encounter, and the second with direct quotes based on recording. The use of impersonal pronouns preserves anonymity of the participants, and the stories serve to link the technical with the social in discussion of the Living Archive as a knowledge infrastructure. 


\section{A user from country}

I am sitting with an Indigenous Australian elder in her remote desert community, relieved that it is not the hot season here, but it is still so dry and dusty on her veranda. We can hear the sounds of the local football competition close by. I sense that she would rather be at the football oval, where the rest of the community has gathered, but she has graciously agreed to sit with me for a bit. A few family members linger nearby, occasionally engaging in our discussion. The elder I am working with has been involved with bilingual education programs in the past, teaching in the local government school for years before the program was shut down. We talk for a while about the old days, when language took a leading role in the classroom, and we share our disappointment that only English is tolerated now. We talk about all those wonderful books that were created to teach vernacular literacy, and how they have been locked away now, protected from harm but also from use. I tell her about our project to collect and digitise the books produced in bilingual programs all around the Territory, to keep them safe and make them available online. She's heard about this project before, and has previously signed a permission form to allow materials she created to be included in the collection.

I invite her to look at the website. She is familiar with digital technologies, using the desktop computers in the community centre to access banking and Centrelink services, with assistance from her grandson or one of the digital mentors employed there. She has used iPads and laptops occasionally with non-Indigenous researchers like me, so she is not daunted by the technology, but neither is she dependent on it, besides relying heavily on her phone to stay connected to family. My screen is hard to see, with glare and dusty fingerprints, but I call up the homepage. I've managed to access the wifi, but it is quite slow, and I am conscious of not wanting to use up the community's small allocation. ${ }^{10}$

The home page of the Living Archive site presents a map of the Northern Territory, marked out in a mosaic of colours representing the different language areas. Tropical regions near the coast are coloured various shades of green, while in the desert region more reds and oranges are used. There are areas of grey, mostly across the middle with some pockets elsewhere, showing regions where the collection lacks materials. As we navigate around the map, different labels appear in response to the movement of the cursor, displaying the names of languages or places. I show her how to use the controls to zoom in to a certain area, then back out to the bigger picture, and how to tick a box to display the names of the languages or the places - it gets too crowded when they're all visible, so we switch that feature off. The coloured icons marking locations use different colours to differentiate various producers of literacy materials: red for the Literature Production Centres (LPCs) set up in many of the government schools with bilingual programs, blue for Literacy 
Centres at some of the smaller programs, purple for the Catholic or Independent schools which had bilingual programs, green for community language centres, and yellow for communities that produced language materials without any of these infrastructures. We find the coloured area corresponding to her language, and click on the icon for her community, revealing a handful of book covers to the right of the map. I explain how clicking on one of the books will take us into the archive to see the whole book with pictures, or just in text form.

But she stops and wants to look at the map a bit longer. I zoom in further, embarrassed by the sharp edges of the polygons that become visible if you go in too far. I remember the long discussions between the project team, graphic designer and programmer about how to present the map. How far should users be able to zoom? Should we let them move around the whole world, or zoom in close enough to see buildings in their community? How many latitude and longitude points along the imagined borders of each language region should be marked to define each polygon? More points make the edges smoother, but less definition avoids making claims about boundaries. Should we use standard inverted teardrops to mark locations, or something different? How much detail should there be on the underlying map to help orient the user? We ended up choosing a smooth surface on which to map languages and communities, without further interruption of man-made impositions besides state borders, and only marking communities where materials were produced. She looks carefully at the map of her language region, and those around its borders. Without the marking of roads, rivers or other features, it is difficult to determine exactly how the border has been determined, though there's a tiny bit of topographical detail if you zoom in far enough. Her sister comes and looks, and they talk together in their language. The only words I recognise are names of places or languages, but I can't tell if they're expressing concern or admiration for what they see on the website. The sister wanders off, the elder nods and allows me to continue. I click on a book and we go to a page headed 'Respecting ownership' - I explain that this reminds users about Aboriginal authority over the books, and that the books in the collection mustn't be misused or sold. I click the green button marked 'Yes' and we move on to looking at some books in her language. I show her how to search and browse and download.

As we continue, I find myself talking too much, explaining all about the site and what we have tried to do with it, but I sense that she is becoming less engaged. I thank her for her time, and give her a lift in my rented 4WD to join the rest of the community at the football oval. There she will continue to engage with family in contemporary, dynamic language practices, as she's done for years. I'm struck by the disconnect between this real-life use of language and the digital artefacts I have been sharing from my computer. [figure1] 
As much as I enjoyed my interaction with this elder as a user of the Living Archive website, I was also disconcerted by her apparent loss of interest in the website after we left the map page. Some months later, I received an email from a colleague in Alice Springs, who has shared the website with various schools and individuals through her work with the Department of Education. She said she had become hesitant to show the site sometimes, because people in some communities were 'unhappy with the LAAL map. It has so many wrong boundaries and too many communities in the wrong language group'. This feedback seemed to illuminate the response of the Indigenous elder, alerting me to the agency of the map beyond its affordances as a navigation tool to access the contents of the Archive. Potential users may be wary of its capacities to stir up trouble between users and owners of languages in use in different places. Perhaps the concern is that gathering all these resources in a central repository is actually at odds with Indigenous practices, where knowledge is locally owned and situated. The very construct of an archive requires ongoing negotiation in each of the places represented on the map.

The use of a map as the entry point for the Living Archive was an early decision for the project team. Motivated to maintain the strong connection between language and place and to connect books to stories that circulate in particular places, the plan was to make the digital artefacts accessible through linking mapped language and place names with books in the Archive. We considered the spatiality of a map interface would suit Indigenous Australian users who may prefer to use spatial and visual literacy than text literacy. ${ }^{11}$

A map would also highlight the range of languages across the Northern Territory, situate them, and depict their distribution - many languages cluster closely together on the coast, but spread widely across the sparsely populated desert. It was hoped the use of colour could highlight the absence of collected materials from certain areas, implicitly inviting potential users to offer materials in order to bring colour to those regions. The project team was conscious of the politics of mapping, how different maps 'show different kinds of arguments and audiences, and different ways of dealing with the problem, or not dealing with it'. ${ }^{12}$ We were reluctant to assert any authority in mapping language boundaries, but rather to use abstract shapes as points of access to the books in the collection associated with that language or region. The map is purposefully designed as an explicit oversimplification, to function largely symbolically. ${ }^{13}$ This approach was chosen as an alternative to attempting accurate representations of the detailed geography of language areas or the complex multilingualism of many communities, to avoid giving the false impression that only one language is spoken in each region. This oversimplification of linguistic and spatial distribution is only one of several embedded in the design of the Archive, offering one way of representing complex information in a usable form. The choice of language names and spelling is also a 
conscious decision, using the names as presented in the material in the Archive, rather than on 'official' (yet still highly problematic) sources such as ISO 639-3. ${ }^{14}$

As a point of entry to the Living Archive, the map interface is a node in the network of relations that keep the archive going; technically, politically, socially and ontologically. The processes behind these relations, the contested boundaries and revisions, the discussions that resulted in specific decisions have become embedded in the working of the map interface itself. There may be some evidence buried in a trail of emails and meeting notes, annotated printouts and screenshots, but these decisions are not visible to the user. Configuring technologies in ways we consider will benefit Indigenous Australian community users of the Archive does not disorient or disadvantage academic users, as it maintains the expected functionality such as standard search and browse options. The development process has taken seriously the imperfect, problematic relation between the technical and social challenges of constructing the digital archive, while somehow managing to work.

\section{A user from the classroom}

The air conditioning in the computer laboratory at the university is an enormous relief from the oppressive Darwin humidity. My colleague from the Computer Science Department has agreed to assist the project team by facilitating a user evaluation of the Living Archive. We're using a thinkaloud protocol to access some of the user's thoughts as they engage with the site, following a sequence of tasks and questions. I am there only as an observer, under instruction not to intervene, even when the user says they cannot do something that I know they could do. As a result, I find the process equal parts illuminating and frustrating.

We have already been through the user evaluation process with two academic researchers, now we are sitting with a non-Indigenous teacher who used to work in a remote Northern Territory school with a bilingual program and an active Literature Production Centre (LPC). She now works in an urban school with a high proportion of Indigenous students, and has tried to incorporate some language into the program, despite her minimal competency in an Indigenous language, and the students’ varied language backgrounds.

After some small talk and collection of basic demographic information, we turn our attention to the Living Archive website. The teacher navigates straight to her old school, and instantly recognises some of the book covers that display next to the map on the home page. She is immediately taken back to the LPC, saying 'I can almost smell what those shelves look like'. She clicks through the map and glances at the 'Respecting ownership' page, saying 'I'm really pleased this is here because I think everyone needs to be reminded that just because it's on the internet it's not open slather.' I 
notice that she does not read through the text on the screen, just clicks the green button that allows her entrance to the Archive.

Identifying a familiar book, she fondly recalls the traditional owner who told that story - her classificatory grandmother according to Indigenous kinship connections. She clicks on the cover image and as the PDF opens, she comments 'Wow, so these whole books are on here?' Perhaps she thought it was just a catalogue, a window into a collection that was stored elsewhere, but is clearly delighted to see the entire book with its colourful illustrations and a cultural significance she appreciated without ever fully understanding.

The teacher clicks the 'Download' button, and discovers she can save that book to her own device, noting that the PDF is much more flexible outside the constraints of the online view. She wonders about the 'Text' button, but is disappointed that it reveals only a plain text file, so drab compared to the vibrancy of the book itself. Noticing the English translation at the bottom of the text file, she says it would be good to have this alongside the original language - then remembers that the books were created to focus on the language, with the English text only included as a concession to teachers who could not read or speak the language. Then she wonders if she can cut and paste from the text file to make word cards and worksheets, but hesitates. 'I want to go back and check what I can do with this, I'm conscious that stuff has been ripped off for years, where was that warning again?' She infers that her relationships with people in the community, and her understanding of some of the issues of ownership and sharing of knowledge according to Indigenous law have made her 'overly sensitive, I wouldn’t think twice about ripping it off from any other site'.

She finds the arrows at the side of the screen that allow her to scroll through books one at a time, and notes that 'some of it is really old, I don't think current teachers would use it, but linguists would. There's really new flash stuff available now'. She is curious about one title, wanting to check when it was produced, but no date is provided. Later when she discovers a button that enables different sort options she tries to sort by date, but it is clear that missing dates in the metadata are not handled well by the Archive.

My colleague sets her a task in a different collection of books, so she goes to the opposite end of the map, curious about how different the books would be there. She clearly does not have the same connection to these titles, but more of a detached interest. She notes one author with many books attributed to her and comments 'I'd like to know more about her - is she Indigenous? Is that her western name?' She scrolls through a few books, focusing on ones with interesting images, glossing over the 'boring' ones. She expresses uncertainty as she is presented with a large number of books in a language and from a community she does not know: 'I'm not sure what to do with these.' There is no finding aid to help her filter the results: 'if I was looking for material for a particular class, 
how would I know what to look for?' Remembering a lesson she is developing about turtles, she wonders if there are any relevant stories in the collection - she types the word into the search box and several books appear in various languages. She is again disconcerted: 'I thought it would only find it for the language I was looking at.' None appear to have the word 'turtle' in the title so 'these must be the words in the other languages'. But how would she know which books might be appropriate for a year 9 science class? She browses through the results, a mix of stories about hunting and cooking turtles, some more scientific texts about the life cycle and habits of turtles, and some creation stories - but she does not comment on the different genres. I think she is simply enjoying the nice pictures of turtles.

She filters for the category 'Song' and clicks on some book covers, asking 'Can I hear the songs? It's not much good if they're just written, I want to hear them'. She thinks about how she might use some materials from the Archive in her current teaching role, where not all the Indigenous students have strong connections to language: 'I could display the book on the interactive whiteboard ... but it would be hard to use if we can't hear the language.' She is not sure how her students would manage navigating the site and says 'it might be nice to have an avatar come to explain stuff'. But she can see potential for using some of the materials in her lessons - 'I'd make sure it was all downloaded and ready' - and decides she could explore more, ending the session with 'I know what I'll be doing this weekend.' [figure2]

This interaction with a teacher left me disconcerted in quite a different way than my experience of working with the Indigenous elder as archive user. It was encouraging to see someone with a connection to the materials and a purpose for engaging with them, but her use of the Archive also highlighted many of the absences and shortcomings of the website and the project work which underlies the site. Several times I have heard users lament the lack of audio - many people who can understand the language but are not literate are excluded from interacting with the materials in certain ways. Yet text-to-speech technology is a long way from automating the process without butchering the pronunciation, and our nascent efforts to record speakers reading books aloud have been limited by time and resources. The 'old stuff' in the collection offers opportunities for updating and reworking materials in and for the classroom, engaging students with technologies and stories and people and curriculum, but these affordances may not be visible within the site itself, and busy teachers may not have time or energy to take up the opportunities therein.

The teacher's uncertainty about what to do when faced with a wide range of resources in languages she is not familiar with piqued my interest. Many of the potential users of the Archive will lack connection to any community or language represented therein, and will need to find ways 
to navigate the socio-technical relation of thousands of books in dozens of languages. I am constantly seeking more books in more languages, forgetting how overwhelming it may be to some users. I wrote an article suggesting ways of using materials in the Living Archive to resource the cross-curriculum priority of incorporating Aboriginal and Torres Strait Islander histories and cultures in all learning areas of the Australian Curriculum. ${ }^{15}$ The technical arrangement of the Archive is not prescriptive about its navigation. As a project team we had discussed issues of categorisation and classification of materials in the Archive, concerned with serving the needs of non-Indigenous users but wanting to avoid the imposition of a non-Indigenous (mainstream Australian anglophone) set of categories on the corpus. One of the project team has written extensively about the structures of metadata reducing rather than enhancing the productive and creative ways in which words in Aboriginal languages relate and connect across categories, and privilege a western objectivist ontology. ${ }^{16}$ The materials are forced into certain configurations by the existing metadata and the technical requirements of the database. We chose to limit the browse options to 'Language,' 'Place' and 'People,' and build the search tool to search both metadata and data. While this fails to achieve Christie's unattainable ideal of creating an 'ontologically flat and epistemologically innocent database' which encodes no assumptions about the nature of the world and of knowledge, ${ }^{17}$ it works towards this by structuring the data at a basic level in terms familiar to both Indigenous and non-Indigenous users, supporting multiple ontologies. These behind-the-scenes negotiations result in an interface that both requires and enables users to make their own connections as they navigate the collection.

The teacher's desire to show respect for the materials by adhering to the conditions was encouraging, as I expect users unfamiliar with Indigenous ownership of story to be less concerned by these issues. The 'green button' that acts as a technological gatekeeper to allow or prevent entry to the Archive subjects the user to a regime of copyright law which establishes certain restrictions around use and distribution of materials. The text on the 'Respecting Ownership' page highlights the Indigenous ownership of the stories and briefly outlines what users can and cannot do with the materials in the Archive. Permission was granted by the holders of both copyright and moral rights to publish the books online under a Creative Commons license. Though the text on this page was carefully worded, there is minimal expectation of careful reading, and it barely scratches the surface of the complex interaction of Indigenous and non-Indigenous understandings of intellectual property. ${ }^{18}$. By clicking the green 'Yes' button, the user agrees to participate in this regime and is permitted entry to the collection. The Indigenous elder may have rejected this invitation to engage with the materials because of concerns about the representations made by the map, while the 
teacher accepted the invitation, mindful that this would demand certain behaviours of her as she engaged with the materials.

\section{Online survey outcomes}

As the Living Archive website was designed to be completely open access, with no barriers to entry such as logins or passwords, it has been difficult to gauge user activity on the site. Google Analytics give some raw figures about page views, number of users, average time spent, etc. ${ }^{19}$ however this information provides little insight into our users and their motivation and engagement. To fill this gap, a simple online survey was created to seek user feedback.

The survey was open for one month in 2018, and promoted on the project's newsletter list and social media channels. A total of 55 people responded to questions about their use of the Archive, along with some basic demographic information. ${ }^{20}$ This very small sample indicated that most users are non-Indigenous, living in cities or regional towns, but many have some connection with an Australian Indigenous language or community. Users identified as researchers, students, teachers, with a range of 'other' types. Around half have visited the site more than five times, and the most common acquisition was via ‘friend/word of mouth’ followed by social media. Most respondents said they would visit the site again and tell someone else about it, with some saying they would share content for educational or personal purposes, and the most positive responses ranked access to materials, ease of navigation and selection of materials most highly.

Some of the concerns expressed by the users reported here were echoed in the qualitative feedback from the survey, particularly the desire for the inclusion of audio materials. The teacher's concerns about respectful use of the materials were also reflected in some responses, with requests that the materials be 'updated and improved' or 'corrected, edited and augmented so that they are more usable'. Such comments reflect the tension identified in the project between safeguarding the integrity of the original publications and wanting them to be dynamic and usable in contemporary contexts.

Like the two user stories reported here, there was a general satisfaction that these cultural heritage materials were now available online, with comments such as 'fabulous archives and love that material is open access' and 'a great resource, particularly for a non-indigenous teacher like me!' Like the teacher story reported here, having a 'connection' with an Indigenous language or community appears to be a key indication of engagement, giving people a purpose and target for their navigation of the site. There was no discussion of the map interface or its claims, which may appear less salient to non-Indigenous users than to Indigenous Australians. The social aspect of the 
connection to place or language is enhanced in this project by the technical components, which configure the materials and the users in specific ways.

The survey data gave some indication of use of the Archive, but is clearly skewed to those already familiar with the project and sympathetic to its goals. It was not expected to deliver a comprehensive overview of the user base, and in particular was unlikely to evoke responses from remote Indigenous community members, for whom an online survey is not an effective way to elicit feedback. The results of the survey reflected this bias, and therefore represents only a very small and supportive population of users.

\section{Imagining an Archive}

I began this paper with a quotation from the first academic article the project team published, not long after the Living Archive website had gone live. The stories of user interactions related above recall 'the different moment-by-moment decisions made by countless people who, little by little make it what it is.' The quote foregrounds the often unacknowledged truth that to a large extent the project team was making it up as we went along, not recklessly but with care, in order 'to fulfil the somewhat ill-defined purposes which, in our original funding application, we claimed it would serve'. ${ }^{21}$ I was curious to consider the purposes envisaged in the original application to the Australian Research Council (ARC) in 2011, prior to my involvement as project manager. In revisiting the application document, I sought to relate the particular socio-technical arrangement that was proposed in the application to what actually came to life over the next few years - the Archive that the users in my two stories and survey participants experienced.

The motivation for the application was a shared concern for the fate of printed materials produced for bilingual education programs in the Northern Territory from 1974 to the 2000s. The ARC's Linkage, Infrastructure, Equipment and Facilities grant scheme is typically used in the natural sciences to fund machinery and tools to facilitate research. An application to collect and digitise vulnerable materials from remote Indigenous communities as infrastructure for humanities and social sciences researchers was relatively unusual and the success of the application was somewhat surprising to the applicants.

The historical context of the application probably contributed to its success. Bilingual education programs in remote schools in the Northern Territory have been through various waves of policy since their establishment in the mid-1970s. ${ }^{22}$ By the early 2000s, only a few programs continued, and these were undermined by the 2008 decision to mandate the first four hours of the school day for tuition in English, relegating first language programs to the margins of the school curriculum. This widely-criticised decision contrasted with increased international concern over the 
fate of Indigenous languages, ${ }^{23}$ with a renewed emphasis on language documentation and description of endangered languages, and the importance and value of language in education generally and in Indigenous contexts specifically. ${ }^{24}$

These policy fluctuations had left vulnerable the vast range of materials produced for vernacular literacy education in these programs. In 2012, a parliamentary enquiry into language learning in Indigenous communities recommended 'improving community access to language materials through a dedicated Indigenous languages archive at the Australian Institute of Aboriginal and Torres Strait Islander Studies (AIATSIS) and the sharing of resources with schools and educational institutions'. ${ }^{25}$ AIATSIS, Australia’s leading research, collections and publishing institution in the field of Australian Indigenous studies, was undergoing a review, and there were concerns about its capacity to collect and digitise materials, with long waiting times for communities wanting access to their own materials in the collections. ${ }^{26}$ In this context of heightened awareness of the need for digital preservation of cultural heritage material, the timing of the Living Archive proposal was significant and the funding application was successful. I was employed on a one-year contract to manage the project, though my background is in linguistics rather than archiving or data management.

In revisiting the origins of this knowledge infrastructure, it is worth considering the characteristics of the institutions involved. The application required a 'linkage' between organisations: in this case Charles Darwin University (CDU), a small, young institution based in Australia's smallest and northernmost capital; the Australian National University (ANU), a medium-sized, prestigious, highly-ranked institution in the nation's capital; and the Northern Territory Department of Education, which oversaw the bilingual education programs and under whose auspices most of the materials which would make up the collection were created. Beyond partnership between institutions, the application was a collaboration between individuals employed by those organisations, all with close ties with Indigenous communities. Two of the chief investigators had been involved in bilingual education programs in northeast Arnhem Land, and the other connected with various language groups in Central Australia. ${ }^{27}$ Similarly, the main collaborators from the government belonged to the Department of Education's Indigenous Language and Culture team, and also had particular connections with language communities across the Territory. Cognisant that grant funders look for both individual and institutional capacity, the application highlighted CDU’s long history of institutional involvement with Indigenous communities and languages, including the longstanding Yolngu Studies program, the innovative Teaching from Country project, and a previous ARC project on Indigenous Knowledge and Resource Management in Northern Australia. ${ }^{28}$ ANU highlighted the researchers and projects that 
would benefit from the development of such an archive, including linguistic, anthropological, ethnomusicological work, and the Centre for Aboriginal Economic Policy Research. It seems that ANU had the profile to attract funding for a project of this nature, but its close connections with AIATSIS and PARADISEC precluded it from creating a separate archive for this material, while CDU had the capacity and on-the-ground connections to run the project but not the profile to attract Category 1 funding. The inclusion of the Department of Education as a partner was complex and strategic: their financial and in-kind contribution indicated an investment in the future of the pedagogical products of the bilingual education era, while their policy no longer actively supported bilingual programs from which these products emerged and could continue to be actively used. They also held copyright over the majority of the materials that made their way into the Living Archive.

The original funding application included several assumptions. First it claimed that there was no existing archive suitable for housing this collection; second it insisted that the Archive should be digital; and third that the work of collecting and digitising hard copies could be achieved in one year. The practice of sending hard copies of books published to the National Library of Australia or AIATSIS makes the materials available to those outside the communities of origin, though it can also have the effect of distancing books from those same communities. New digital infrastructure programs were putting internet access and mobile technologies into remote communities. So a digital archive would have the dual purpose of preserving the materials in a form that could be re-awakened and re-purposed, while also making access possible (in digital forms) for people for whom the books were physically inaccessible. The one-year time-frame was an unrealistic goal, but careful budgeting meant the funds extended to two years, and a second application was successful.. Sustainability beyond the funding cycle was provided by CDU Library's offer to host the materials on institutional servers, also providing professional advice on metadata and scanning. ${ }^{29}$

Concerns about copyright and intellectual property issues are surprisingly absent from the original application, yet from the early days of project work, this topic created much discussion and absorbed much time within the project team. We were not dealing with the type of materials that are often discussed in the literature about Indigenous knowledge in archival collections, where Indigenous people are the subjects of the record and not the owners. ${ }^{30}$ Instead, the Archive contains materials created largely by and for Indigenous users as part of an ostensibly two-way education system, and is consequently subject to the requirements of two knowledge traditions regarding copyright and intellectual property. The original application looks somewhat naïve in its lack of discussion of these issues that ended up taking a great deal of time and energy to find a working 
(though not completely satisfactory) solution, involving copyright agreements, permission forms and Creative Commons licenses. ${ }^{31}$

In reviewing the original application, it is possible to discern a tension between what the applicants were hoping to achieve and what the ARC might be willing to fund. It seems that compromises were necessary to obtain funding and to acknowledge the various institutional agendas. Meanwhile the owners of the stories and languages embedded in textual form in the books were rather marginal to the application itself. The benefit to academic researchers was aligned with the value to Indigenous authorities, and how the latter would be supported to engage in ongoing collaborative and multidisciplinary research with interested users. Over the seven-year life of the project, this has yet to materialise. There are various possible reasons for this, including that Aboriginal language users and owners were never very interested in the literature in the first place because the idea of preserving knowledge in a printed artefact conflicts with their dynamic language practices. ${ }^{32}$ According to Christie, for Indigenous people "the textual objects in the archive are not seen to be representing a world "out there" or "back then" - they are material traces of previous episodes of creative collective action which can now be reinvigorated in new contexts of collective creation'. ${ }^{33}$ So while the goal is to preserve and make accessible these artefacts of Indigenous knowledge-making practices, the project has had to use technologies of archiving which appear to be antithetical to traditional Indigenous practices of preserving and sustaining knowledge.

\section{Conclusion}

In recording contrasting stories of the Living Archive in use - though under somewhat contrived conditions - and juxtaposing these with a review of the aspirations of the funding applicants, I offer a view of the diverse range of socio-technical arrangements which bring to life a digital archive of literature in Australian Indigenous languages. The project was envisaged by a group of academics with shared concerns and assorted priorities, each with different conceptions of what the Archive might become, attending to their own institutional obligations and seeking to meet the needs of diverse audiences. The Archive was subject to certain technical requirements and expectations determined by the project and has become a knowledge infrastructure that is now available and in use in various contexts. The stories of user interactions expose some of the consequences of those moment-by-moment decisions made by the project team. These entailed various updates and reconfigurations, the formulation of careful wording about authorship, ownership and use, intricate workflows, complex metadata schemas, and ongoing negotiations. Yet the experiences of sitting beside users as they offer commentary on their navigation of the Archive are not solely a product of the configuration of the website and its contents. They also draw on the users' own roles and 
associations with the languages, books, people, locations, pedagogies and technologies, and the complex interconnections of all these things. The means by which the map configures a specific view of the language and literary landscape of the Northern Territory, the presence and absence of facets and filters to support or inhibit certain kinds of navigation, the means of observing and respecting different legal practices - are just some of the many socio-technical arrangements embedded in the Archive.

Having been intimately connected with this project as it has come to life over the last seven years, I see its strengths and weaknesses, its uniqueness and its idiosyncrasies, its affordances and constraints, recalling the arguments won and lost, the ideas envisioned and redirected. I still have faith that by digitising collections such as these books that were produced in specific educational contexts with their particular classroom-oriented language practices, and by making them freely available online, the Living Archive opens up possibilities for Indigenous community members to engage in (re)interpreting, (re)presenting and (re)using these materials through a trusted repository. While their form as written text makes them somewhat peripheral to collective Indigenous language practices, such a digital archive is still 'highly relevant to the civil, political and legal rights of Aboriginal people and, importantly, their ability to enjoy these rights. ${ }^{34}$

The socio-technical approach considers the individual and institutional or communal creators, stakeholders, audiences and their interaction with the technologies of archiving, digitisation, storage, access, display, navigation, etc. in a complex web. The social will change, as will the technical, so our efforts are necessarily provisional. The project team's goal has been to establish the Living Archive in a careful and respectful way that will allow multiple ontological interactions, new connections and activities as people discover, access and interact with the content now and into the future. The project was undertaken to preserve endangered literature for contemporary and future uses, to support multiple ontologies and enable multiple epistemic interactions. Time will tell if the Living Archive has a re-colonising effect or results in Indigenous language authorities reclaiming these knowledge artefacts. Perhaps in the future when language practices have changed, the value of these remnants of previous language practices will be reassessed, as some old wordlists and narratives of missionaries or pastoralists in the early days of settlement have become rich sources for Indigenous groups whose living language heritage has largely disappeared.

Figure 1. Screenshot of the home page of the Living Archive of Aboriginal Languages. 


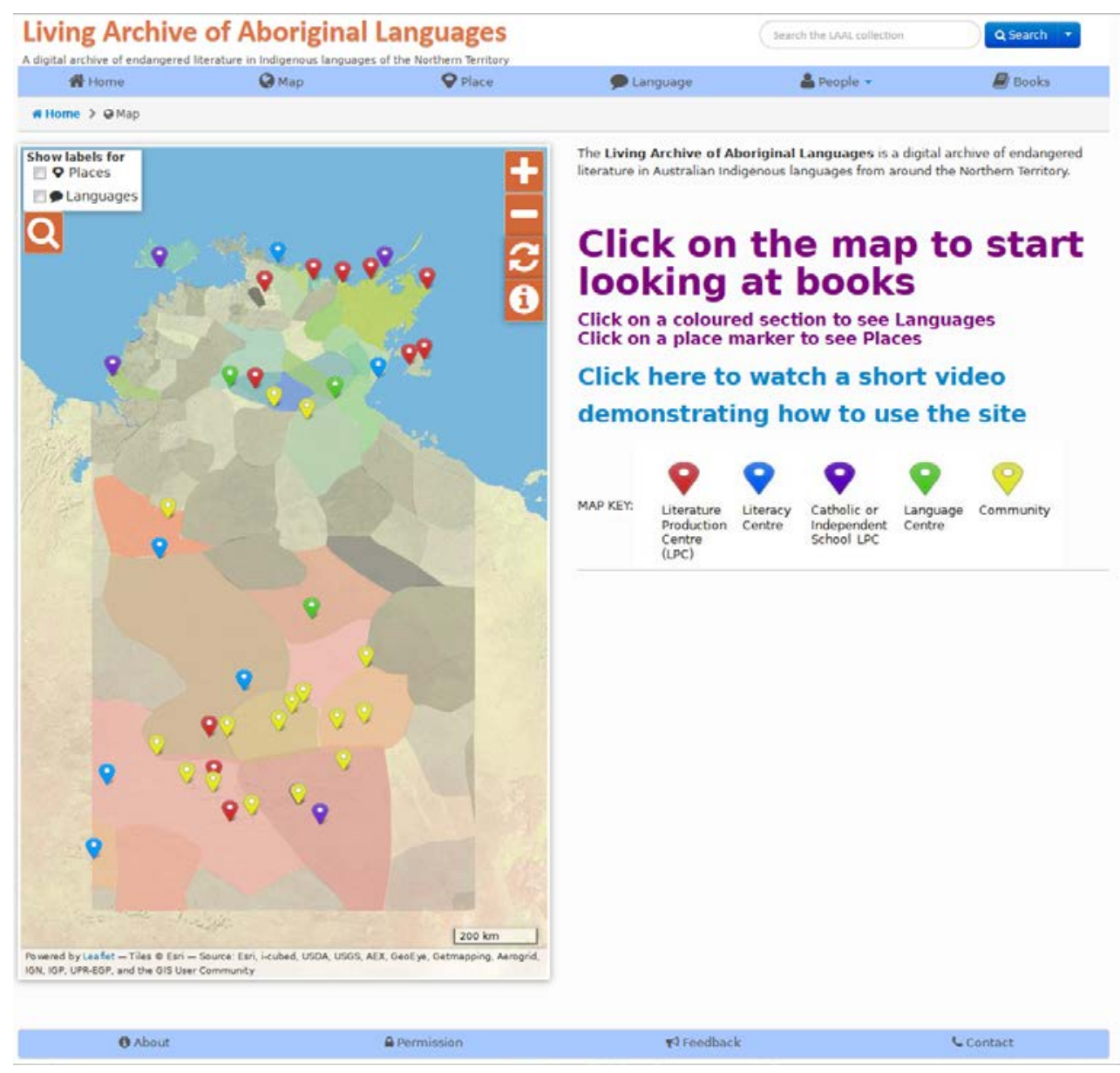


Figure 2. Screenshot of the results of a search for the word 'turtle' in the Living Archive of

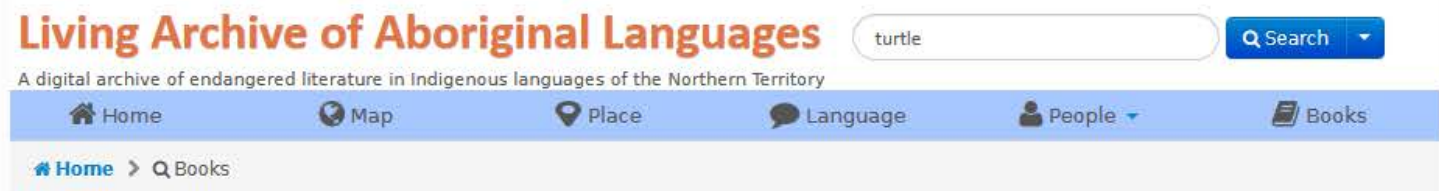

137 books
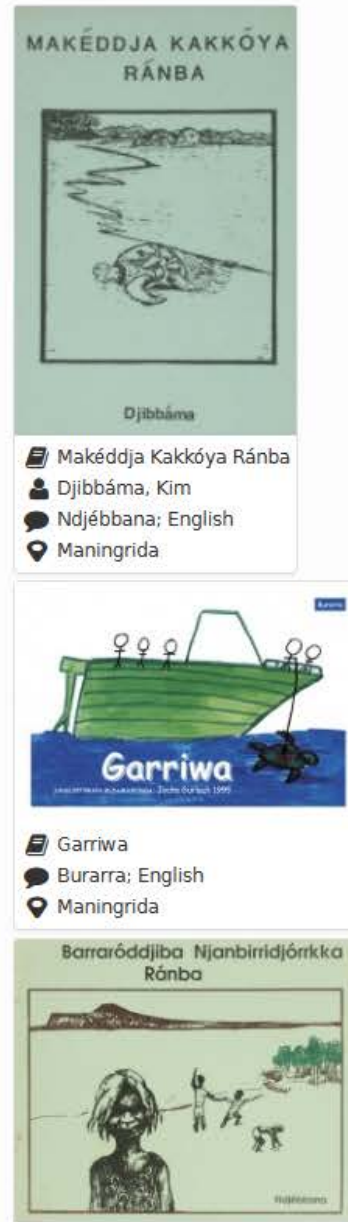

G] Barraróddjiba njanbirridjórrkka ránba

Wilton, Monica

Ndjébbana; English

Maningrida

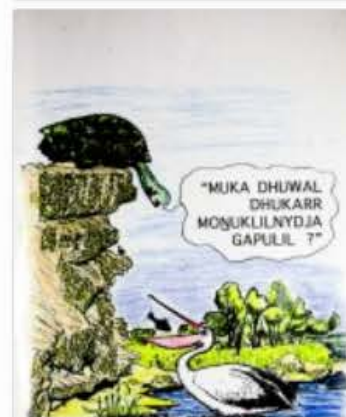

g] Muka Dhuwal Dhukarr Monuklilnydja Gapulit?

2 [Beattie, Pat]

Djambarrpuynu; Yolnu Matha [multiple languages]

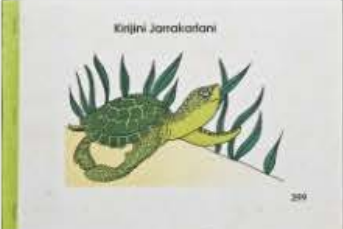

E) Kirijini Jarrakalani

2 Kerinaiua, Marguerita

- Tiwi; English

- Nguiu (Wurrumiyanga)

Makéddja barrúra barra-ngódjbara-nja

E. Makéddja barrúra barra-

ngódjbara-nja

- Ndjébbana; English

- Maningrida

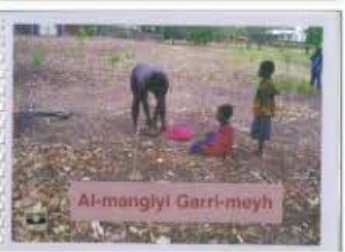

(6) Al-mangiyi garri-meyh

a Galmur, Judy

Jawoyn; English

- Barunga

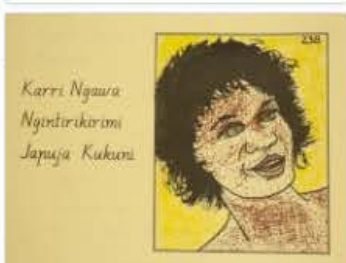

G Karri Ngawa Ngintirikirimi Japuja Kukuni

2 Kerinaiua, Marguerita

- Tiwi; English

9 Nguiu (Wurrumiyanga)

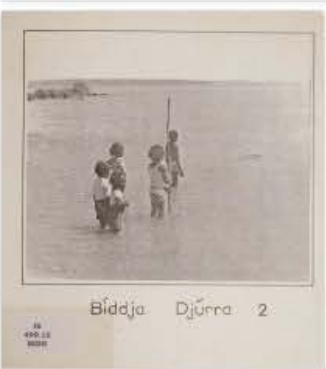

E) Bíddja Djúrra 2

- Ndjébbana; English

O Maningrida
\#Grid झList IE Relevance -

Nyirring Leyhmay Wurroyung?

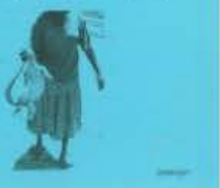

E) Nyirring leyhmay wurruyung?

2. Galmur, Judy; Katherine,

Margaret

- Jawoyn; Kriol; English

Barunga

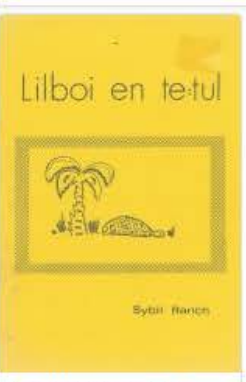

Lilboi en te:tul

Kriol; English

- Barunga

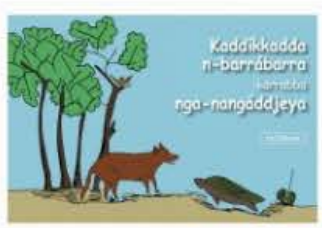

G) Kaddíkkadda n-barrábarra

karrabba nga-nangáddjeya

2. Mamariyi, Melanie

- Ndjébbana; English

- Maningrida

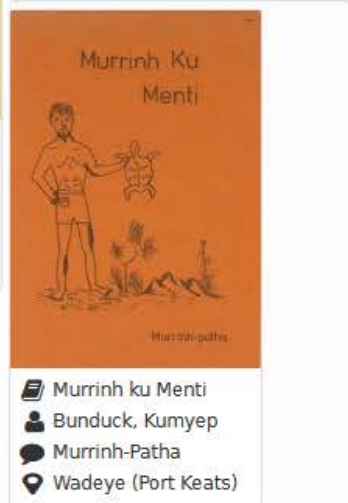

Wadeye (Port Keats)

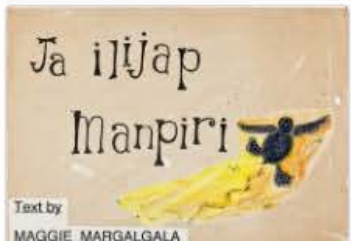

\section{Filter}

- Author (72)

7 Kelantumama, Magdalen

7 Kerinaiua, Marguerita

5 Brennan, Queenie

5. Lalara, Gula

- Place $(18) \oplus$

36 Maningrida

24 Nguiu (Wurrumiyanga)

12 Barunga

12 Milingimbi

部 Category (6) +

67 Narrative

22 Language instruction

19 Instruction.

14 Traditional

- Illustrator (55)

8 Puruntatameri, Ancilla

7 Westblade, Brett

6 Kerinaiua, Fiona

4 Kerinaiua, Marguerita

- Language (32) +

101 English

25 Ndjébbana

24 Tiwi

17 Yoinu Matha [multiple

languages] 
${ }^{1}$ M Christie, B Devlin and C Bow, 'The Birth of the Living Archive: An emerging archive of Australian Aboriginal languages and literature', Archifacts, October, 2014, pp. 48-63, pp. 52-53.

${ }^{2}$ The Living Archive of Aboriginal Languages is supported under the Australian Research Council's Linkage, Infrastructure, Equipment and Facilities funding scheme (LE120100016 and LE140100063). The author's research is supported by an Australian Government Research Training Program Scholarship. The project is also discussed in: C Bow, M Christie and B Devlin, 'Developing a Living Archive of Aboriginal Languages', Language Documentation and Conservation, vol. 8, 2014, pp. 345-360; C Bow, M Christie and B Devlin, 'Shoehorning complex metadata in the Living Archive of Aboriginal Languages', in A Harris, N Thieberger and L Barwick (eds), Research, Records and Responsibility: Ten years of PARADISEC, Sydney University Press, Sydney, 2015, pp. 115-131; C Bow, M Christie and B Devlin, 'Digital futures for bilingual books', in BC Devlin, S Disbray and NRF Devlin (eds), History of Bilingual Education in the Northern Territory: People, Programs and Policies, Springer, Singapore, 2017, pp. 347-353.

${ }^{3}$ DM. Levy, 'Documents and Libraries: A Sociotechnical Perspective', in Ann Peterson Bishop, Nancy A. Van House and Barbara Pfeil Buttenfield (eds), Digital Library Use: Social Practice in Design and Evaluation, MIT Press, Cambridge, MA, 2003, p. 33.

${ }^{4}$ For language documentation see for example PK Austin, 'Language documentation in the 21st century', JournaLIPP, no. 3, 2014, pp. 57-71; R Henke and AL Berez-Kroeker, 'A Brief History of Archiving in Language Documentation, with an Annotated Bibliography', Language Documentation and Conservation, vol. 10, Emergent Use and Conceptualization of Language Archives, 2016, pp. 411-457; K Rice and N Thieberger, 'Tools and technology for language documentation and revitalization', in KL Rehg and L Campbell (eds), The Oxford Handbook of Endangered Languages, Oxford University Press, Oxford; New York, 2018. For the role of libraries in Indigenous knowledge spaces see for example M Nakata, A Byrne, V Nakata and G Gardiner, 'Indigenous Knowledge, the Library and Information Service Sector, and Protocols', Australian Academic and Research Libraries, vol. 36, no. 2, 2005, pp. 7-21; M Nakata and M Langton, Australian Indigenous Knowledge and Libraries, Australian Academic and Research Libraries, v. 36, no, 2, 1 June 2005, pp. 1-211; S Nicholls, L Booker, K Thorpe, M Jackson, C Girault, R Briggs and C Jones, 'From principle to practice: community consultation regarding access to Indigenous language material in archival records at the State Library of New South Wales', Archives and Manuscripts, vol. 44, no. 3, 2016, pp. 1-14; K Thorpe and M Galassi, 'Rediscovering Indigenous Languages: The Role and Impact of Libraries and Archives in Cultural Revitalisation', Australian Academic and Research Libraries, vol. 45, no. 2, 2014, pp. 81-100. For work on Indigenous knowledge practices in digital contexts see for example M Christie, 'Computer Databases and Aboriginal Knowledge', Learning Communities: International Journal of Learning in Social Contexts, vol. 1, 2004, pp. 4-12; M Christie, 'Words, Ontologies and Aboriginal Databases', Media International Australia, Incorporating Culture and Policy, vol. 116, 2005, pp. 52-63; H Verran, M Christie, B. Anbins-King, T Van Weeren, and W. Yunupingu, 'Designing digital knowledge management tools with Aboriginal Australians,' Digital Creativity, v. 18, no.3, 2007, pp. 129-142.

${ }^{5}$ For example R Amery, Warraparna Kaurna! Reclaiming an Australian language, University of Adelaide Press, Adelaide, S.A., 2016; J Giacon, Yaluu. A recovery grammar of Yuwaalaraay and Gamilaraay: a description of two New South Wales languages based on 160 years of records, Asia-Pacific Linguistics, College of Asia and the Pacific, The Australian National University, Canberra, ACT, 2017.

${ }^{6}$ M Nakata, V Nakata, G Gardiner, J McKeough, A Byrne and J Gibson, 'Indigenous Digital Collections: An Early Look at the Organisation and Culture Interface', Australian Academic and Research Libraries, vol. 39, no. 4, 2008, p. 233-4.

${ }^{7}$ GC Bowker, K Baker, F Millerand and D Ribes, ‘Toward Information Infrastructure Studies: Ways of Knowing in a Networked Environment', in J Hunsinger, L Klastrup and M Allen (eds), International Handbook of Internet Research, Springer Netherlands, Dordrecht, 2009, pp. 97-117; PN Edwards, SJ Jackson, MK Chalmers, GC Bowker, D Ribes, M Burton and S Calvert, Knowledge Infrastructures: Intellectual Frameworks and Research Challenges, Deep Blue, Ann Arbor, MI, 2013, p. 41; H Karasti, F 
Millerand, CM Hine and GC Bowker, 'Knowledge infrastructures: Part I', Science and Technology Studies, vol. 29, no. 1, 2016, pp. 2-12.

${ }^{8} \mathrm{C}$ Waterton, 'Experimenting with the Archive: STS-ers As Analysts and Co-constructors of Databases and Other Archival Forms', Science, Technology, and Human Values, vol. 35, no. 5, 2010, pp. 645-676, p. 647.

${ }^{9}$ SL Star, 'Infrastructure and ethnographic practice: Working on the fringes', Scandinavian Journal of Information Systems, vol. 14, no. 2, 2002, pp. 107-122; KF Gracy, 'Documenting Communities of Practice: Making the Case for Archival Ethnography’, Archival Science, vol. 4, no. 3-4, 2004, pp. 335365.

${ }^{10}$ Later a mobile app was developed to enable offline access to materials from the Archive CorrelLink, LAAL Reader, Charles Darwin University, Darwin, N.T., 2015.

${ }^{11}$ Christie et al., 'The Birth of the Living Archive', p. 58.

${ }^{12}$ Star, 'Infrastructure and ethnographic practice', p. 114.

${ }^{13}$ For discussion of the use of 'technologies of representation' in the performativity of Indigenous knowledges, see $\mathrm{H}$ Verran and M Christie, 'Using/designing digital technologies of representation in Aboriginal Australian knowledge practices', Human Technology, vol. 3, no. 2, 2007, pp. 214-227.

${ }^{14}$ SIL International, ISO 639-3, ISO 3 Registration Authority, 2015, viewed 31 May 2017, <http://www01.sil.org/iso639-3/default.asp>; JA Bickford, 'The ethics of language identification and ISO 639', Listening: Journal of Communication Ethics, Religion, and Culture, vol. 51, no. 1, 2016, pp. 21-34.

${ }^{15} \mathrm{C}$ Bow, 'Using authentic language resources to incorporate Indigenous knowledges across the Australian Curriculum', Learning Communities: International Journal of Learning in Social Contexts, vol. 20, 2016, pp. 20-39.

${ }^{16}$ M Christie, 'Computer Databases and Aboriginal Knowledge', Learning Communities: International Journal of Learning in Social Contexts, vol. 1, 2004, pp. 4-12; M Christie, 'Words, Ontologies and Aboriginal Databases', Media International Australia, Incorporating Culture and Policy, vol. 116, 2005, pp. 52-63; M Christie, 'Boundaries and Accountabilities in Computer-Assisted Ethnobotany', Research and Practice in Technology Enhanced Learning, vol. 1, no. 3, 2006, pp. 285-296; Verran and Christie, 'Using/Designing Digital technologies of Representation in Aboriginal Australian Knowledge practices'.

${ }^{17}$ Christie, 'Words, Ontologies and Aboriginal Databases', p. 60.

${ }^{18} \mathrm{C}$ Bow and P Hepworth, 'Observing and respecting diverse knowledge traditions in a digital archive of Indigenous language materials', Journal of Copyright in Education and Librarianship, vol. IN PRESS, 2018.

${ }^{19}$ Google Analytics showed that in the 12 months from 1 October 2017 the site had over 6000 visits from 3870 users, of which $84 \%$ were new visitors, and that each user spent an average of 11 minutes and visited 4.5 pages per session, leading to a total of 27,556 overall page views in one year. This gives an average of just over 16 visits and 10 users per day, and $84 \%$ of users were in Australia.

${ }^{20}$ A more complete report on the outcomes of the survey can be found at the project's blog site at http://livingarchive.cdu.edu.au/survey-outcomes/

${ }^{21}$ Christie et al., 'The Birth of the Living Archive’, pp. 52-53.

${ }^{22} \mathrm{C}$ Nicholls, 'Death by a Thousand Cuts: Indigenous Language Bilingual Education Programmes in the Northern Territory of Australia, 1972-1998', International Journal of Bilingual Education and Bilingualism, vol. 8, no. 2-3, 2005, pp. 160-177; B Devlin, S Disbray and N Devlin, 'A Thematic History of Bilingual Education in the Northern Territory', in BC Devlin, S Disbray and NRF Devlin (eds), History of Bilingual Education in the Northern Territory, Springer, Singapore, 2017, pp. 1-10.

${ }^{23}$ B Devlin, 'Policy Change in 2008: Evidence-Based or a Knee-Jerk Response?', in BC Devlin, S Disbray and NRF Devlin (eds), History of Bilingual Education in the Northern Territory, Springer, Singapore, 2017, pp. 203-218; J Oldfield, 'Anangu Muru Wunka - Talking Black Fella: A Critical Policy Analysis of the Northern Territory First Four Hours of English', PhD, University of Melbourne, Melbourne, 2016; J Simpson, J Caffery and P McConvell, Gaps in Australia's Indigenous Language Policy: Dismantling bilingual education in the Northern Territory, AIATSIS Discussion Paper, Australian Institute of Aboriginal and Torres Strait Islander Studies, Canberra, 2009.

${ }^{24}$ NP Himmelmann, 'Documentary and descriptive linguistics', Linguistics, vol. 3, no. 6, 1998, pp. 161-196. UNESCO, Education in a multilingual world, UNESCO Education Position Paper, United Nations 
Educational, Scientific and Cultural Organization, Paris, 2003; NH Hornberger, 'Multilingual education policy and practice: Ten certainties (grounded in Indigenous experience)', Language Teaching, vol. 42, no. 2, 2009, pp. 197-211.

${ }^{25}$ House of Representatives Standing Committee on Aboriginal and Torres Strait Islander Affairs, Our Land Our Languages: Language Learning in Indigenous Communities, The Parliament of the Commonwealth of Australia, Canberra, ACT, 17 September 2012. p.viii.

${ }^{26}$ ACIL Allen Consulting, M Rose and M McMillan, Australian Institute of Aboriginal and Torres Strait Islander Studies Independent Review, ACIL Allen Consulting, Brisbane, QLD, 2014, p. 165. Concerns about wait times are mentioned in House of Representatives Standing Committee on Aboriginal and Torres Strait Islander Affairs, Our Land Our Languages, pp. 207-208.

${ }^{27}$ M Christie, 'Developing Local Curriculum Materials - Learning Metaphors, Insightful Collaborations, Community Involvement', in B Devlin, S Disbray and NRF Devlin (eds), History of Bilingual Education in the Northern Territory, Springer, Singapore, 2017, pp. 113-126; B Devlin, 'Language Maintenance in a Northeast Arnhem Land Settlement', EdD, Columbia University, New York, 1986; J Simpson, Warlpiri morpho-syntax: A lexicalist approach, vol. 23, Springer Science and Business Media, Dordrecht, 1991; J Simpson, 'Warumungu (Australian - Pama-Nyungan)', in A Spencer and AM Zwicky (eds), The Handbook of Morphology, Blackwell, Oxford, 1998, pp. 707-736.

${ }^{28}$ M Christie, 'Yolngu Studies: A case study of Aboriginal community engagement', Gateways: International Journal of Community Research and Engagement, vol. 1, 2008, pp. 31-47; M Christie, 'Engaging with Australian Indigenous Knowledge Systems: Charles Darwin University and the Yolngu of Northeast Arnhem Land', Learning Communities: International Journal of Learning in Social Contexts, vol. 7, 2009, pp. 23-35; M Christie, Teaching from Country: Increasing the Participation of Indigenous Knowledge Holders in Tertiary Teaching Through the Use of Emerging Digital Technologies, Australian Learning and Teaching Council, Strawberry Hills, NSW, 2010; M Christie, 'Teaching from country, learning from country', Learning Communities: International Journal of Learning in Social Contexts, vol. 2, 2010, pp. 6-17; M Christie, H Verran and W Gaykamangu, IKRMNA - making collective memory with computers, Indigenous Knowledge and Resource Management in Northern Australia, 2003.

${ }^{29}$ J Mamtora and C Bow, 'Towards a Unique Archive of Aboriginal Languages: A Collaborative Project', Journal of the Australian Library and Information Association, vol. 66, no. 1, 2017, pp. 28-41.

${ }^{30} \mathrm{~J}$ Anderson, 'The Making of Indigenous Knowledge in Intellectual Property Law in Australia', International Journal of Cultural Property, vol. 12, no. 3, 2005, pp. 345-371; L Iacovino, 'Rethinking archival, ethical and legal frameworks for records of Indigenous Australian communities: a participant relationship model of rights and responsibilities', Archival Science, vol. 10, no. 4, 2010, pp. 353-372; T Janke and L Iacovino, 'Keeping cultures alive: archives and Indigenous cultural and intellectual property rights’, Archival Science, vol. 12, no. 2, 2012, pp. 151-171; S McKemmish, S Faulkhead, L Iacovino and K Thorpe, 'Australian Indigenous knowledge and the archives: embracing multiple ways of knowing and keeping', Archives and Manuscripts, vol. 38, no. 1, 2010, pp. 27-50; K Thorpe, 'Aboriginal Community Archives: A Case Study in Ethical Community Research', in AJ Gilliland, S McKemmish and AJ Lau (eds), Research in the Archival Multiverse, Monash University Publishing, 2017, pp. 900-934.

${ }^{31}$ Bow and Hepworth, 'Observing and respecting diverse knowledge traditions.'

${ }^{32}$ Christie reflecting on his role as teacher-linguist in a bilingual school program saw unutilised books as 'ten years of linguistic work continuing to lie on the shelves, rarely having been used in a classroom: a constant reminder that Yolngu teachers and their students were never impressed for a moment by the illusion of objective knowledge we had tried to conjure within each cover, a sign of Yolngu resistance to colonisation' M Christie, 'Drawing the Line - A History of Yolngu Literacy', in D Myers (ed.), Reinventing Literacy - the Multicultural Imperative, Phaedrus Books, Rockhampton, QLD, 1995, p. 80.

${ }^{33}$ Christie et al., 'The Birth of the Living Archive', p. 55.

${ }^{34} \mathrm{~L}$ Ormond-Parker and R Sloggett, 'Local archives and community collecting in the digital age', Archival Science, vol. 12, no. 2, 2012, p. 195. 